\title{
Evidence for the evolution of a single component phenol/cresol hydroxylase from a multicomponent toluene monooxygenase
}

\author{
$\mathrm{RH}$ Olsen, JJ Kukor ${ }^{1}$, AM Byrne ${ }^{2}$ and GR Johnson ${ }^{3}$ \\ Department of Microbiology and Immunology, University of Michigan Medical School, Ann Arbor, Michigan 48109-0620, \\ USA
}

We have previously reported on the organization of a unique toluene-3-monooxygenase pathway for the degradation of alkyl-substituted petroleum hydrocarbons including characteristics of the second step in the pathway transforming phenols to catechols. In the present work we have focused on the regulation and unusual genetic organization of this metabolic step. In particular, we have sequenced the 3-kb DNA interval between the region encoding the $t b u D$ gene product (phenol/cresol hydroxylase) and part of the toluene-3-monooxygenase operon of strain PKO1. Then, various regions of this DNA were fused to a LacZ expression system to ascertain the location of the tbuD gene promoter and the binding site for its regulator, TbuT. The $5^{\prime}$ end for transcripts for the putative promoter of the $t b u D$ gene was also analyzed using primer extension analysis. Collectively, these results revealed that the promoter was located 2.5-kb upstream of the region encoding the tbuD gene product whose $\mathrm{N}$-terminal region had been previously determined by peptide sequencing. Remarkably, the intervening 2.5-kb region showed sequence identity to results we reported previously for a multi-subunit toluene-2-monooxygenase cloned from a different bacterium, strain JS150, for which phenols are also substrates and effectors. When the DNA sequence for the tbuD gene and its contiguous 2.5-kb upstream region were compared to the entire toluene-2-monooxygenase sequence cloned from strain JS150, a promoter proximal region encoding three reading frames showed $99 \%$ identity to subunits for the toluene-2-monooxygenase operon. Within the contiguous $t b u D$ gene region, however, DNA sequence homology was reduced to $64 \%$ overall identity and deduced amino acid sequence homology was only $21 \%$ similar. Although regions internal to the $t b u D$ gene showed homology to corresponding toluene-2-monooxygenase subunits, domains associated with the putative functions proposed for such subunits were deleted. We believe that these results suggest that through evolution either tbuD was derived from the 2-monooxygenase pathway by deletions and molecular rearrangements, or alternatively the $t b u D$ gene recruited part of the 2-monooxygenase pathway and its regulatory system which is activated by benzene, alkyl-substituted benzenes and phenols.

Keywords: Burkholderia pickettii PKO1; Pseudomonas sp strain JS150; phenol hydroxylase; multicomponent oxygenases; molecular evolution; transcriptional regulation

\section{Introduction}

We have investigated Burkholderia pickettii PKO1 as a model organism for determination at the molecular genetic level of features that may relate to its unique physiological ability to utilize aromatic petroleum hydrocarbons in oxygen-limited (hypoxic) aquifer environments. The toluene pathway from strain PKO1 has been cloned as a 26.5-kbp DNA fragment, designated pRO1957. The $t b u$ regulon is comprised of four operons as shown in Figure 1. Transcription starting points are depicted as circles with arrows for each of the operons. The transcriptional activator that controls the $t b u$ regulon is the NtrC-like protein, TbuT [5].

Correspondence: Dr RH Olsen, Department of Microbiology and Immunology, 5608 Medical Sciences Bldg II, University of Michigan Medical School, Ann Arbor, MI 48109-0620, USA

${ }^{1}$ Present address: Center for Agricultural Molecular Biology, Foran Hall, Dudley Road, Cook College, Rutgers University, PO Box 231, New Brunswick, NJ 08903-0231, USA

${ }^{2}$ Present address: Department of Biologic and Materials Sciences, University of Michigan School of Dentistry

3Present address: AL/EQC - OL, 139 Barnes Drive, Suite 2, Tyndall AFB, FL 32403, USA

This paper is dedicated to Professor David T Gibson for his many contributions to our understanding of microbial biochemistry.

Received 2 July 1997; accepted 22 July 1997
TbuT, in combination with appropriate low-molecularweight effectors, regulates the expression of the toluene3-monooxygenase locus, tbuAlUBVA2C [4], the catechol meta-cleavage operon, tbuWEFGKIHJ [14], and a locus designated $t b u X$, the precise function of which is unknown at this point [6]. The regulatory gene, $t b u T$, is expressed as the result of a cascade. Transcription of tbuT occurs by readthrough transcription from the toluene-3-monooxygenase promoter when an effector, such as toluene, benzene, ethylbenzene, trichloroethylene or $m$-cresol, is present [5].

In the present work we have focused on the regulation and unusual genetic organization of the second step in the tbu catabolic pathway which transforms phenols to catechols and which is encoded by $t b u D$. We have previously reported the sequence of $t b u D$ and have purified and characterized the flavoprotein monooxygenase encoded by it [15]. In our previous work we demonstrated that $t b u D$ was expressed from a 3.1-kb HindIII fragment of pRO1957, however we were not able to demonstrate regulated $t b u D$ expression from this fragment when the regulatory gene, tbuT, was present in trans. 


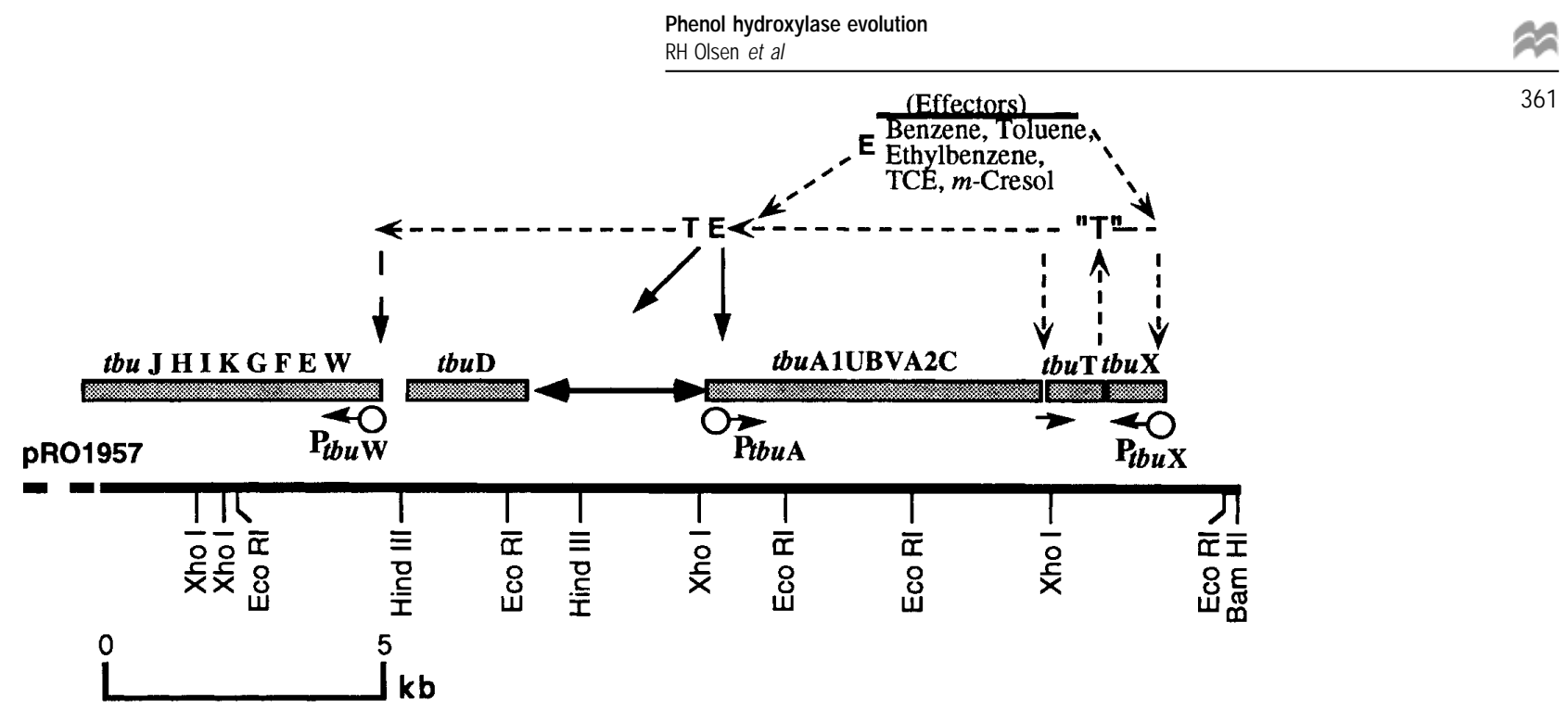

Figure 1 Organization of the $t b u$ regulon of $B$. pickettii PKO1. The transcriptional activator, TbuT (T), interacts with low molecular weight effectors (E) resulting in initiation of transcription from the $t b u A 1 U B V A 2 C, t b u W E F G K I H J$, and $t b u X$ operons. The double-headed arrow between $t b u D$ and $t b u A 1$ indicates the DNA region investigated in the present study. Details are given in the text.

\section{Materials and methods}

Bacterial strains, plasmids, and culture conditions

The bacterial strains and plasmids used in this study are described in Table 1. Pseudomonas putida PPO200 was routinely cultured on plate count complex medium (TN) [24] at $30^{\circ} \mathrm{C}$, and $P$. aeruginosa PAO1c was cultured on $\mathrm{TN}$ medium at $37^{\circ} \mathrm{C}$. E. coli strains DH5 $\alpha$ and BL21 were cultured on Luria-Bertani medium [26] at $37^{\circ} \mathrm{C}$. For maintenance of plasmids in $P$. aeruginosa PAO1c, carbenicillin was added to media at $500 \mu \mathrm{g} \mathrm{ml}^{-1}$, and trimethoprim was added at $600 \mu \mathrm{g} \mathrm{ml}^{-1}$. For plasmid maintenance in $E$. coli strains, ampicillin was added to media at $100 \mathrm{mg} \mathrm{ml}^{-1}$. For $P$. putida PPO200 carrying pKRZ1 constructs, kanamycin was added to media at $60 \mu \mathrm{g} \mathrm{ml}^{-1}$, and for pRO1614 con- structs, tetracycline was added to media at $25 \mu \mathrm{g} \mathrm{ml}^{-1}$. Isopropyl- $\beta$-d -thiogalactopyranoside (IPTG) and 5-bromo-4chloro-3-indolyl- $\beta$-d-galactopyranoside $(\mathrm{X}-\mathrm{Gal})$ were used in solid media at concentrations of 50 and $80 \mu \mathrm{g} \mathrm{ml} \mathrm{m}^{-1}$, respectively.

\section{Molecular techniques}

Plasmids were introduced into $E$. coli by the procedure of Hanahan [9] and into $P$. aeruginosa by the procedure of Mercer and Loutit [18]. Plasmid pKRZ1 and its derivatives were introduced into $P$. putida PPO200 by electroporation using the method of Smith and Iglewski [29]. Restriction endonuclease digestion and molecular cloning were done as described previously [22]. DNA for sequencing was rou-

Table 1 Bacterial strains and plasmids used in this study

\begin{tabular}{|c|c|c|}
\hline Strain or plasmid & Relevant marker(s) ${ }^{a}$ & Reference or derivation \\
\hline \multicolumn{3}{|l|}{ Strains } \\
\hline \multicolumn{3}{|l|}{ E. coli } \\
\hline DH5 $\alpha$ & $\begin{array}{l}\mathrm{F}^{-} \Phi 80 \mathrm{~d} l a c Z \Delta \mathrm{M} 15 \Delta(\text { lacZYA-argF }) \mathrm{U} 169 \\
\text { deoR recA1 endA1 phoA hsdR17 } \\
\left(r_{\mathrm{K}}^{-}, m_{\mathrm{K}}^{+}\right) \text {supE44 } \lambda^{-} \text {thi-1 gyrA96 relA1 }\end{array}$ & [9] \\
\hline BL21 & $\mathrm{F}^{-} \operatorname{ompT}\left(\mathrm{r}_{\mathrm{B}}^{-}, \mathrm{m}_{\mathrm{B}}^{-}\right)$ & {$[30]$} \\
\hline P. aeruginosa PAO1c & Prototroph & {$[10]$} \\
\hline P. putida $\mathrm{PPO} 200^{b}$ & Prototroph & [31] \\
\hline \multicolumn{3}{|l|}{ Plasmids } \\
\hline pKRZ1 & $\begin{array}{l}{ }^{1} \text { lac } Z \mathrm{Ap}^{\mathrm{r}} \mathrm{Km}^{\mathrm{r}} ; 13.3-\mathrm{kb} \text { promoter } \\
\text { probe vector }\end{array}$ & {$[25]$} \\
\hline pBluescript II $\mathrm{KS}^{+}$ & lacZAp $^{\mathrm{r}} ; 2.96-\mathrm{kb}$ cloning vector & Stratagene Cloning Systems \\
\hline pRO1963 & $\mathrm{Cb}^{\mathrm{r}}$ tbuD & [13] \\
\hline pRO2354 & $\mathrm{Tp}^{\mathrm{r}} t b u T$ & {$[23]$} \\
\hline pRO1614::3.1-kb tbuT & $\mathrm{Tc}^{\mathrm{r}} t b u T$ & {$[5]$} \\
\hline pBS::7.2-kb tbuD & $\mathrm{Ap}^{\mathrm{r}} t b u D$ tbuWE & $\begin{array}{l}\text { 7.2-kb XhoI-SacI fragment of pRO1957 } \\
\text { [13] cloned into pBluescript }\end{array}$ \\
\hline $\begin{array}{l}\text { pKRZ1:pRO1963: } \\
\text { XhoI-BglII }\end{array}$ & $A p^{\mathrm{r}} \mathrm{Km}^{\mathrm{r}} t b u D^{\prime}$ & $\begin{array}{l}\text { 3.4-kb XhoI-BglII fragment of pRO } 1957 \\
\text { [13] cloned into SalI and BamHI-cleaved } \\
\text { pKRZ1 }\end{array}$ \\
\hline
\end{tabular}

${ }^{a}$ Abbreviations: $\mathrm{Cb}^{\mathrm{r}}, \mathrm{Tp}^{\mathrm{r}}, \mathrm{Tc}^{\mathrm{r}}, \mathrm{Ap}^{\mathrm{r}}, \mathrm{Km}^{\mathrm{r}}$, resistance to carbenicillin, trimethoprim, tetracycline, ampicillin, kanamycin, respectively.

${ }^{b} P$. putida PPO200 is a derivative of strain mt- 2 cured of its TOL plasmid. 

and was further purified by passage through Qiagen (Qiagen Inc, Chatsworth, CA, USA) tips as recommended by the supplier. Plasmid pBluescript II $\mathrm{KS}^{+}$(Stratagene Cloning Systems, La Jolla, CA, USA) was used to construct the subclones necessary for DNA sequencing. Ordered deletions of overlapping subclones were made by previously described procedures [15]. Nucleotide sequences were determined directly from plasmids by the dideoxy chain termination technique [27] using T3 and T7 primers (Stratagene). Sequencing reactions were performed with the modified T7 polymerase, Sequenase version 1.0, and a Sequenase kit (United States Biochemical Co, Cleveland, $\mathrm{OH}, \mathrm{USA}$ ) as recommended by the supplier, except that dITP was used in place of dGTP to eliminate band compression in $\mathrm{GC}$-rich regions.

\section{DNA sequence analysis}

A complete double-stranded composite sequence was assembled from sequenced fragments with AssemblyLIGN sequence assembly software (Oxford Molecular Group, Oxford, UK). Nucleotide and deduced amino acid sequences were analyzed with MacVector version 4.5.3 sequence analysis software (Oxford Molecular Group).

\section{Quantitation of promoter activity}

Promoter activity was determined by assaying $\beta$-galactosidase activity in cells of $P$. putida PPO200 carrying pKRZ1 derivatives in trans with tbuT cloned as a $3.1-\mathrm{kb}$ $E c o$ RI-PvuII fragment on the compatible plasmid, pRO1614. P. putida PPO200 cells that carried test plasmids were grown overnight in TN broth that contained kanamycin $\left(60 \mu \mathrm{g} \mathrm{ml}^{-1}\right)$ and tetracycline $\left(25 \mu \mathrm{g} \mathrm{ml}^{-1}\right)$, to select for maintenance of pKRZ1- and pRO1614-based plasmids, and $2.5 \mathrm{mM}$ of either phenol or toluene as effectors. $\beta$-Galactosidase activity was assayed as described by Miller [19], except that cells were permeabilized by addition to chloroform and sodium dodecyl sulfate. $\beta$-Galactosidase activity values are expressed in units as specified by Miller [19].

\section{$R N A$ isolation and primer extension analysis}

Total RNA was isolated from toluene-induced and uninduced cells of $P$. putida PPO200 carrying pKRZ1:pRO1963:XhoI-BglII in trans with a 3.1-kb EcoRIStuI DNA fragment expressing tbuT carried on plasmid vector pRO1614. Typically, cells of $P$. putida PPO200 carrying these constructs were grown in stoppered 150-ml flasks containing $25 \mathrm{ml}$ of MMO basal salts medium [7] with $0.3 \%$ Casamino Acids (Difco Laboratories, Detroit, MI, USA), appropriate antibiotics, and $2.5 \mathrm{mM}$ toluene (added neat). Uninduced cultures were grown in the absence of toluene. Cultures were incubated at $30^{\circ} \mathrm{C}$ in an orbital shaker for $18 \mathrm{~h}$ and were subsequently diluted $1: 100$ into the same medium and were grown for an additional $18 \mathrm{~h}$. RNA was extracted from $2 \mathrm{ml}$ of the cultures using Trizol Reagent (Gibco BRL) essentially as described previously [16].

The $5^{\prime}$ ends of transcripts were determined by primer extension analysis with oligonucleotide primer $5^{\prime}$-AGCAACAGGTCGACACTCAGTTCGG, which was complementary to nucleotides 2-26 of the nucleotide sequence. Primer

labeling with $\left[\gamma^{3}{ }^{32} \mathrm{P}\right] \mathrm{ATP}$, template annealing and extension reactions were performed as described previously [16] except that oligonucleotides were annealed with RNA in hybridization buffer at $95^{\circ} \mathrm{C}$ for $3 \mathrm{~min}$, transferred to $60^{\circ} \mathrm{C}$ for $30 \mathrm{~min}$, and then were slowly cooled to $42^{\circ} \mathrm{C}$ for 15 min.

\section{Protein analysis}

For protein analysis, 100-ml cultures of P. aeruginosa PAO1c carrying pRO1963 (a 7-kb XhoI-HindIII fragment of pRO1957 that contains $t b u D$ and its upstream promoter region) and $\mathrm{pRO} 2354$ (which contains $t b u T$ on a compatible plasmid vector) were grown in MMO medium with $0.3 \%$ Casamino Acids plus $0.5 \mathrm{mM}$ phenol at $37^{\circ} \mathrm{C}$ to an $A_{425}$ of 1.5. Cells were harvested by centrifugation and washed twice in $10 \mathrm{ml}$ of $50 \mathrm{mM}$ Tris hydrochloride, $\mathrm{pH} 6.8$. Washed cells were then broken by sonic oscillation using multiple 15-s, 200-W bursts with a Braun-Sonic 2000 apparatus, and cellular debris was removed by centrifugation at $100000 \times g$ for $30 \mathrm{~min}$. Similarly, 100 -ml cultures of $E$. coli BL21 carrying pBluescript II $\mathrm{KS}^{+}:: 7.2-\mathrm{kb}$ tbuD (which contains a 7.2-kb XhoI-SacI fragment of pRO1957 that contains $t b u D$ and its upstream region oriented so that transcription is controlled by the lac promoter of pBluescript) were grown in Luria-Bertani medium plus $0.5 \mathrm{mM}$ IPTG. Cells were harvested and broken as described for the $P$. aeruginosa cultures. The cleared supernatant solutions were used immediately for denaturing gel electrophoresis.

Denaturing gel electrophoresis was performed on sodium dodecyl sulfate (SDS)-polyacrylamide gels by the method of Laemmli [17]. Samples were boiled for $5 \mathrm{~min}$ in solubilization buffer (64 mM $\beta$-mercaptoethanol $2 \% \quad$ SDS, $0.4 \mathrm{mM}$ phenylmethylsulfonyl fluoride, $12.5 \%$ glycerol, $0.05 \%$ bromphenol blue in $10 \mathrm{mM}$ Tris, $\mathrm{pH} 6.8$ ). Gels were run for $30 \mathrm{~min}$ at $100 \mathrm{~V}$ through a $4 \%$ acrylamide stacking gel and a further $3 \mathrm{~h}$ at $200 \mathrm{~V}$ through either 10,12 or $15 \%$ acrylamide separating gels. Protein standards used for molecular mass estimation and their approximate molecular masses in kilodaltons were: myosin, 205; $\beta$-galactosidase, 116; phosphorylase B, 97.4; bovine albumin, 66; ovalbumin, 45; glyceraldehyde-3-phosphate dehydrogenase, 36; carbonic anhydrase, 29; trypsinogen, 24; trypsin inhibitor, 20; $\alpha$-lactalbumin, 14.2. To visualize proteins, the gels were stained with Coomassie brilliant blue R-250.

\section{Analysis of phenol hydroxylase activity}

For phenol hydroxylase assays, cells of $P$. aeruginosa PAO1c carrying pRO1963 and pRO2354 were grown in $100 \mathrm{ml}$ of MMO medium with $0.3 \%$ Casamino Acids, appropriate antibiotics, plus $0.5 \mathrm{mM}$ phenol (or without phenol for uninduced cultures) to an $A_{425}$ of 1.5. Cells of E. coli $\mathrm{BL} 21$ carrying pBluescript II $\mathrm{KS}^{+}:: 7.2-\mathrm{kb} t b u D$ were grown in Luria-Bertani medium plus $0.5 \mathrm{mM}$ IPTG (or without IPTG for uninduced cultures) to an $A_{425}$ of 1.5. Cells were harvested by centrifugation and washed twice in $10 \mathrm{ml}$ of $50 \mathrm{mM}$ sodium phosphate buffer ( $\mathrm{pH}$ 7.6) containing $1 \mathrm{mM} \beta$-mercaptoethanol, $0.1 \mathrm{mM} \mathrm{EDTA,} \mathrm{and}$ $1 \mu \mathrm{M}$ flavin adenine dinucleotide. Washed cells were then broken by sonic oscillation using multiple 15-s, 200-W bursts with a Braun-Sonic 2000 apparatus, and cellular 
debris was removed by centrifugation at $100000 \times g$ for $30 \mathrm{~min}$. Cleared supernatant solutions were used for phenol hydroxylase assays as described previously [13]. Protein was determined by the method of Bradford [3].

\section{Chemicals}

All aromatic hydrocarbons were obtained from Aldrich Chemical Co (Milwaukee, WI, USA) and were used without further purification. Bacteriological medium components were purchased from Difco. Enzymes and reagents for nucleic acid manipulations were purchased from GibcoBRL (Gaithersburg, MD, USA), Boehringer Mannheim Biochemicals (Indianapolis, IN, USA), Stratagene Cloning Systems, Promega Corp (Madison, WI, USA), United States Biochemical Corp, and Qiagen Inc and were used as suggested by the suppliers. Sodium ampicillin, tetracycline hydrochloride, kanamycin monosulfate and trimethoprim (2,4-diamino-5-[3,4,5-trimethoxybenzyl]-pyrimidine) were obtained from Sigma Chemical Corp (St Louis, MO, USA), and disodium carbenicillin (Geopen) was from Pfizer (New York, NY, USA).

\section{Results}

\section{Locating the tbuD promoter}

In order to identify the $t b u D$ promoter we used a two-plasmid transcriptional fusion assay system. DNA fragments upstream of the $t b u D$ translational start (Figure 2) were fused to the promoterless $l a c Z$ gene on the broad-host-range plasmid pKRZ1 [25]. To provide the necessary trans-activating function, tbuT was cloned as a $3.1-\mathrm{kb} E c o$ RI-PvuII fragment onto a compatible plasmid, pRO1614, and these constructs were introduced by electroporation into Pseudomonas putida $\mathrm{PPO} 200$. Expression was monitored by measuring $\beta$-galactosidase levels from cells grown in the presence or absence of the effectors, toluene or phenol. Results are reported in Figure 2 as Miller units of activity (plus or minus the standard error of the mean) for three separate and independent experiments. From the results shown in Figure 2 it is clear that toluene- or phenol-responsive, TbuT-dependent promoter activity for $t b u D$ is located between the $t b u D$ - proximal SalI and XhoI sites.
Phenol hydroxylase evolution

RH Olsen et al

Analysis of the tbuD promoter

The complete nucleotide sequence of the region between the translational start of $t b u D$ and the translational start of tbuAl was determined. A portion of this sequence is displayed in Figure 3. Downstream of the XhoI site (position 573) are the TbuT-binding site (positions 583-645), sigma 54-dependent promoter (positions 765-799) and transcriptional start site (position 790) for the $t b u A 1 U B V A 2 C$ operon that were determined in our previous work [5]. Upstream of the XhoI site (position 573), sequence inspection revealed a region (positions 413-364) showing extensive nucleotide sequence homology to the palindromic regions upstream of $P u$, the XylR-binding site of the upper TOL operon [1], $P o$, the DmpR-binding site of the $d m p$ operon [28], and Ptbm, the putative TbmR-binding site of the toluene-2monooxygenase operon [12]. In addition, a potential sigma 54-dependent $-24,-12$ promoter sequence was found at positions 235-221. Taken together, these findings are consistent with the LacZ expression results shown in Figure 2 and demonstrate that the $t b u D$ promoter is dependent on TbuT and is separate from the $t b u A 1 U B V A 2 C$ promoter.

\section{Determination of $5^{\prime} \mathrm{mRNA}$ start of tbuD transcript}

In order to determine whether the putative promoter and upstream activating sequences detected by DNA sequence analysis (Figure 3) were associated with the in vivo transcriptional start of the $t b u D$ operon, we performed primer extension analysis. Total RNA was isolated from tolueneinduced and uninduced $P$. putida PPO200 strains carrying pKRZ1::pRO1963 XhoI-BglII in the presence of tbuT in pRO1614. A 25-mer oligonucleotide primer (complementary to the double-overscored sequence in Figure 3, positions 2-26) located $195 \mathrm{bp}$ downstream of the putative sigma 54-dependent promoter, was used. As shown in Figure 4 , the analysis revealed a major toluene-induced transcript (lane 1) with RNA isolated from P. putida PPO200 carrying both pKRZ1::pRO1963 XhoI-BglII and pRO1614::3.1-kb tbuT. Because of the compressions encountered when sequencing this region of DNA (Figure 4, sequencing ladder), we were unable to determine whether the primer extension product corresponded to a transcriptional start at the $\mathrm{G}$, the two $\mathrm{Cs}$, or $\mathrm{G}$ residue

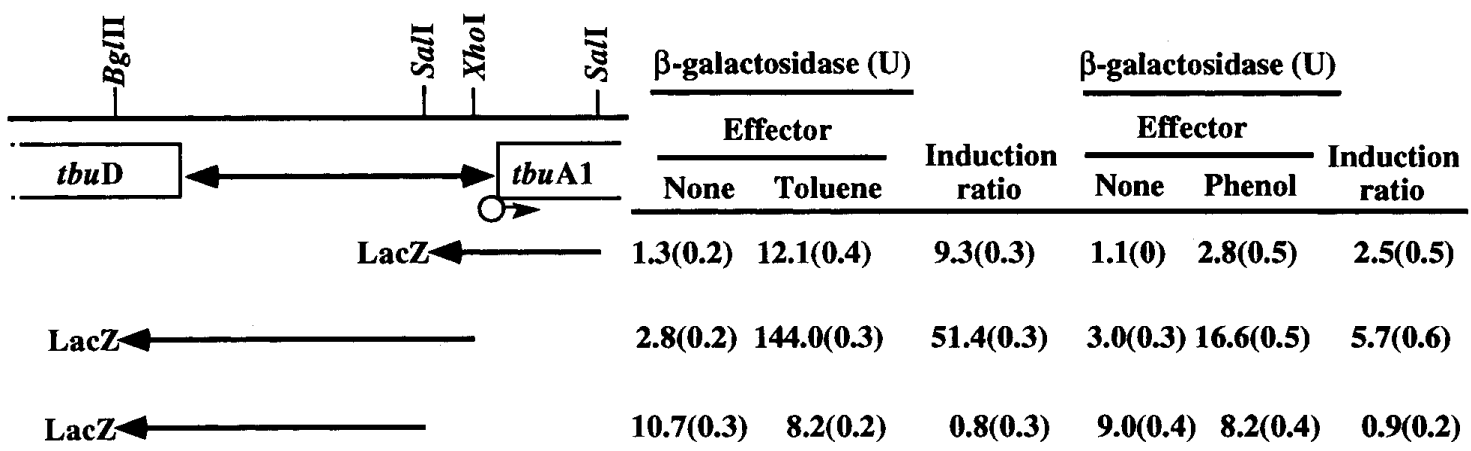

Figure 2 Analysis of the putative $t b u D$ promoter region. The double-headed arrow between $t b u D$ and $t b u A 1$ indicates the DNA region investigated in the present study. The single-headed arrows denote portions of the putative $t b u D$ promoter region that were cloned upstream of the promoterless lac $Z$ gene of pKRZ1. Pertinent restriction endonuclease cleavage sites that bound each cloned insert are shown. To the right of each insert are the corresponding $\beta$-galactosidase values obtained from $P$. putida PPO200 cells carrying the indicated pKRZ1 derivatives in trans with pRO1614::3.1-kb tbuT and grown either in the presence (Toluene or Phenol) or absence (None) of an effector. The results are the average (plus or minus the standard error) of three separate and independent experiments. Induction ratio indicates the ratio of $\beta$-galactosidase determined from effector-induced cells compared with cells grown without an effector. 


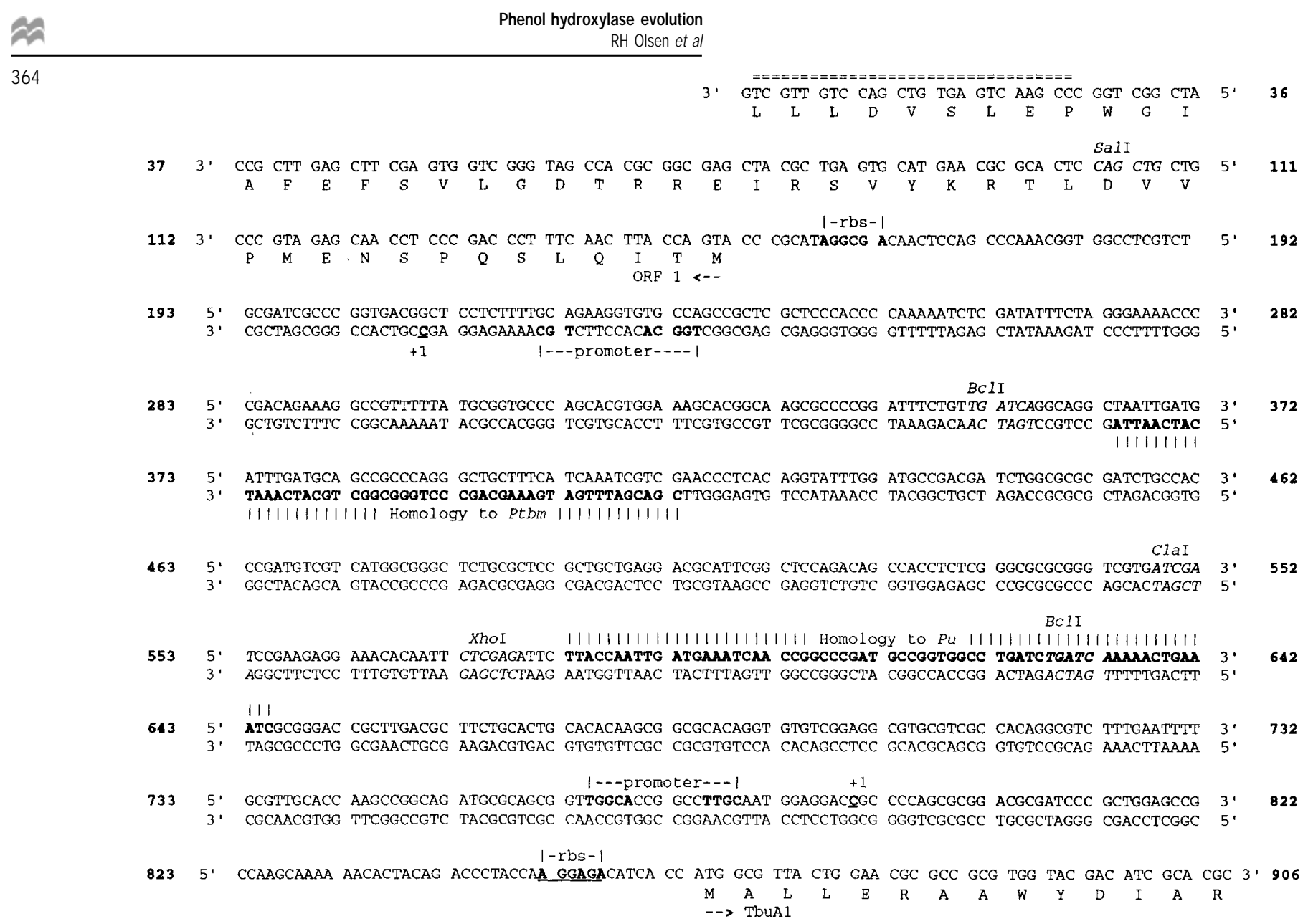

Figure 3 Analysis of the putative $t b u D$ promoter region. The nucleotide sequence between positions 573 and 906 , as well as the functions ascribed to these sequences, are from our previous work [5] and are displayed here for reference. The sequence between positions 413 and 364 , indicated by short vertical lines, shows homology to the TbmR-binding site of the tbm promoter of Pseudomonas sp strain JS150 [12], reported previously by us. At positions 235-221 are the -24 and -12 sequences of a putative promoter. The underlined $\mathrm{C}$ residue at position 210 with a +1 designation indicates the $t b u D$ transcriptional start site as determined by primer extension analysis (described in Results). A putative ribosome-binding site is indicated at positions 163-158. An open reading frame (ORF 1) beginning at position 150 and a portion of its translated sequence are displayed. The double overscore between positions 2 and 26 denotes the sequence complementary to the oligonucleotide primer used in primer extension analysis (described in Results).

complementary to positions $208-211$ in Figure 3. Nonetheless, these results place the start of the transcript at a position consistent with the initiation of transcription from the promoter sequence identified at positions 235-221 (Figure $3)$. This transcript was present at a greatly reduced concentration in uninduced cells (Figure 4, lane 2), which could be due to the promoter being present on a multicopy plasmid in P. putida PPO200. A slightly larger minor transcript was also detected in this analysis, however this transcript was detected at approximately the same concentration in both toluene-induced as well as in uninduced cells, suggesting that a secondary, low level constitutive promoter is present upstream of $t b u D$.

\section{Organization of monooxygenases}

Preliminary analysis of the sequence for the region spanning the $t b u D$ promoter and the structural gene, $t b u D$, suggest a possible relationship to a 2-monooxygenase for which both phenol and alkyl-substituted benzenes are substrates, which we reported previously [12]. The organization of this enzyme (Tbm) for which phenol and cresols are substrates, a multipartite phenol hydroxylase (Dmp) and two monooxygenase enzymes reported by us (Tbu) and others (Tmo) previously [32], is shown in Figure 5. Based on the juxtaposition and size of subunits for which function has been ascribed there seem to be two families of enzymes. However, the substrate range for the phenol hydroxylase ( $d m p$ gene product) from strain CF600 [20] is restricted to phenols, unlike the 2-monooxygenase (tbu gene product) reported by us [12] and an apparently similar enzyme reported previously by others [8].

\section{Nucleotide sequence relationships between the tbuD} phenol hydroxylase and toluene-2-monooxygenase

We have previously characterized a toluene-2-monooxygenase for which phenol is also a substrate [12]. This operon, in turn, is similar in its organization and DNA sequence to a phenol hydroxylase described by others [20], but whose substrate range does not include alkyl-substituted benzenes. The complete nucleotide sequence from the promoter to the start of the structural gene for the unit peptide encoded by $t b u D$ was obtained, and these sequence data have been submitted to the DDBJ/EMBL/GenBank databases under accession number AFO12632. When the 


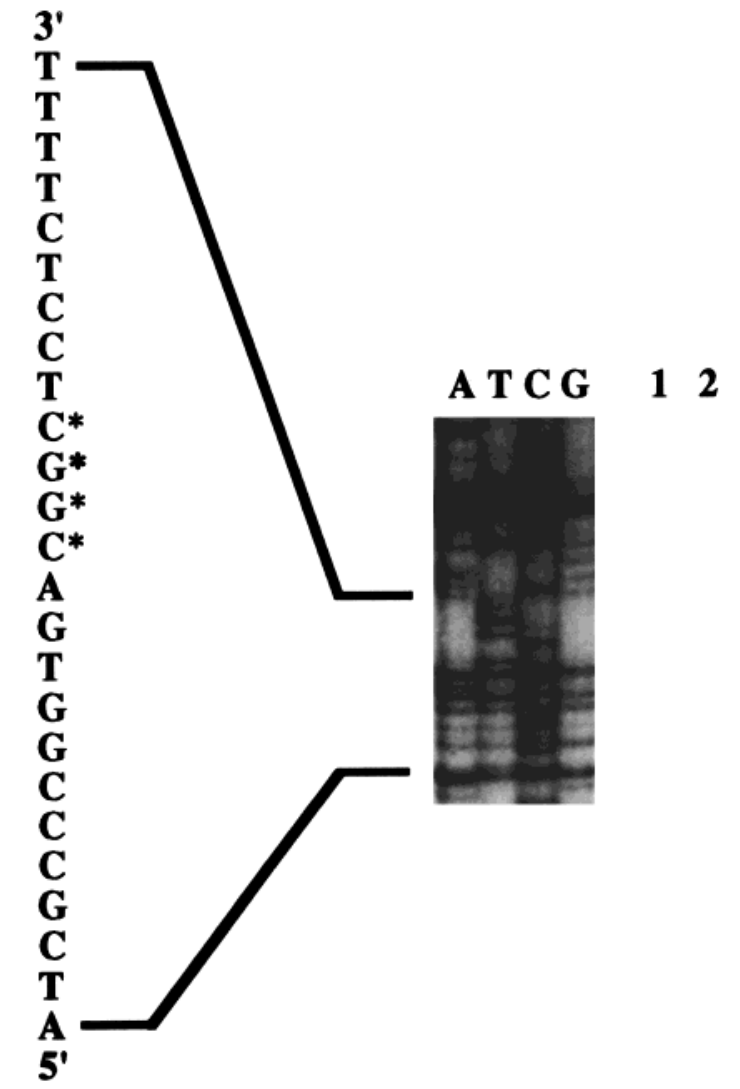

Figure 4 Determination of the $5^{\prime}$ end of the $t b u D$ operon transcript by primer extension analysis. RNA was isolated from $P$. putida PPO200 (pKRZ1:pRO1963 XhoI-BglII + pRO1614:3.1-kb tbuT) grown in the presence (lane 1) and absence (lane 2) of toluene. A sequence ladder using the same oligonucleotide primer and the pBluescript derivative containing the XhoI-BglII fragment is also shown. To the left is an expanded view of the nucleotide sequence surrounding the transcriptional start site (marked with asterisks). Refer to Results for information regarding the marked transcriptional start sites.

\begin{tabular}{l} 
toluene 4-monooxygenase \\
toluene 3-monooxygenase \\
\hline toluene 2-monooxygenase \\
\hline tom
\end{tabular}

Figure 5 Organization of aryl monooxygenases. A schematic representation of the relative sizes and subunit juxtaposition of representatives of two families of six-component aryl monooxygenases is shown. Functions ascribed to subunits are designated by differences in shading. Toluene 4 monooxygenase is from $P$. mendocina KR1 [32], toluene 3-monooxygenase is from $B$. pickettii PKO1 [4], toluene 2-monooxygenase is from Pseudomonas sp strain JS150 [12], and phenol hydroxylase is from Pseudomonas sp strain CF600 [21].

complete sequence from the promoter to the termination of the structural gene for the unit peptide encoded by $t b u D$ was compared as shown in Figure 6, a high degree of identity was obtained between toluene-2-monooxygenase and
Phenol hydroxylase evolution

$\mathrm{RH}$ Olsen et al

the adjacent promoter-distal region for $t b u D$. The first three reading frames of the toluene-2-monooxygenase operon and the corresponding region associated with $t b u D$ were nearly identical. However, when the DNA sequence from the amino- to carboxy-terminal coding region for $t b u D$ was compared to the $t b m F, t b m E$ and part of the $t b m D$ genes for toluene-2-monooxygenase, much less homology was seen. Although within this region there were scattered regions of identity, there were also regions where no identity was found and there were regions where deletions and additions had occurred during the formation of the $t b u D$ gene from a possible progenitor gene such as the toluene-2-monooxygenase operon.

\section{Peptide analysis of the region downstream of the tbuD promoter}

Since the results from $l a c Z$ transcriptional fusion analysis and primer extension analysis both indicated that the $t b u D$ transcriptional start is located $2.5-\mathrm{kb}$ upstream of the translational start of the TbuD peptide, and since DNA sequence analysis of the intervening $2.5-\mathrm{kb}$ region revealed the presence of three open reading frames (ORFs), we sought to determine whether peptide products are produced from these ORFs. The predicted size for the peptide products deduced from the DNA sequence for each of the three ORFs is $10.3,43$ and $11.6 \mathrm{kDa}$. SDS-polyacrylamide gel (SDS-PAGE) electrophoresis of $100000 \times$ g-cleared soluble cellular proteins of $P$. aeruginosa PAO1 carrying pRO1963 (a 7-kb XhoI-HindIII fragment of pRO1957 that contains $t b u D$ and its upstream promoter region) and pRO2354 (which contains tbuT on a compatible plasmid vector), grown in $0.3 \%$ Casamino Acids plus $0.5 \mathrm{mM}$ phenol (Figure 7a, lane 3) revealed a novel peptide band with an apparent $M_{\mathrm{r}}$ of 74000 when visualized in a $10 \%$ polyacrylamide gel. This peptide was not detected in the soluble cellular proteins from uninduced cells (Figure 7a, lane 4). Similarly, SDS-PAGE analysis of soluble cellular proteins from $E$. coli BL21 carrying pBS::7.2-kb tbuD (which contains a 7.2-kb XhoI-SacI fragment of pRO1957 that contains $t b u D$ and its upstream region oriented so that transcription is controlled by the lac promoter of pBluescript), grown in Luria-Bertani medium plus $0.5 \mathrm{mM}$ IPTG, also revealed a novel peptide band with an apparent $M_{\mathrm{r}}$ of 74000 when visualized in a $10 \%$ polyacrylamide gel (Figure 7a, lane 2), which was not present in the soluble cellular proteins from uninduced cells (Figure 7a, lane 1). This peptide corresponds to the size of $\mathrm{TbuD}$, as determined in our previous work $[13,15]$. No novel peptides of approximate $M_{\mathrm{r}}$ of 10300,43000 or 11600 were detected. Since these smaller peptides would not be easily resolved on $10 \%$ polyacrylamide gels, electrophoretic profile analyses were also carried out in $12 \%$ (Figure $7 \mathrm{~b}$ ) and $15 \%$ (Figure $7 \mathrm{c}$ ) polyacrylamide gels. In the $12 \%$ gel, a novel peptide band with an apparent $M_{\mathrm{r}}$ of 74000 was detected in $100000 \times g$ cleared soluble cellular proteins of $P$. aeruginosa PAO1 carrying pRO1963 and pRO2354 grown in the presence of phenol (Figure 7b, lane 2). This peptide was not detected in the soluble cellular proteins from uninduced cells (Figure $7 \mathrm{~b}$, lane 1). In the $15 \%$ gel (Figure 7c) the peptide of $M_{\mathrm{r}}$ 74000 was not detectable owing to the compression of the higher molecular weight peptides at the top of the gel. 


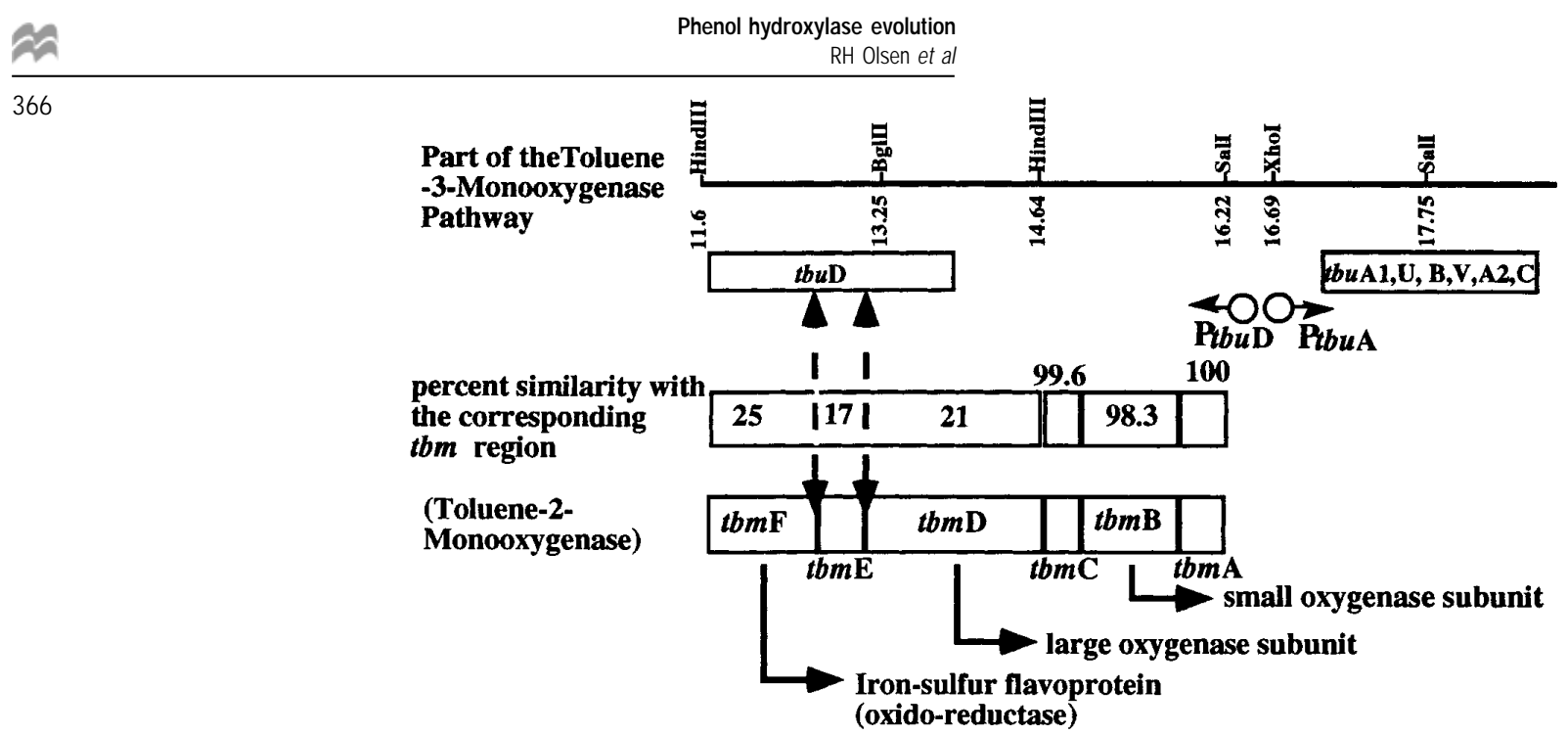

Figure 6 Homology relationships between $t b u D$ and its promoter region from $B$. pickettii PKO1 and the tbm-encoded toluene 2-monooxygenase operon of Pseudomonas sp strain JS150. A portion of the $t b v$-encoded toluene 3-monooxygenase regulon from strain PKO1 is shown in the upper portion of the figure, together with relevant restriction endonuclease cleavage sites and their coordinates from pRO1957 [13]. The locations of the $t b u A 1 U B V A 2 C$ encoded toluene 3-monooxygenase operon and its promoter $\left(\mathrm{P}_{t b u A}\right)$ and the $t b u D$-encoded phenol hydroxylase and its promoter $\left(\mathrm{P}_{t b u D}\right)$ are indicated. Percent similarities between the $t b m$-encoded toluene 2-monooxygenase peptides of strain JS150 and the corresponding regions from strain PKO1 are shown in the rectangles in the center of the figure.

However, in neither the $12 \%$ nor the $15 \%$ gels were peptides of approximate $M_{\mathrm{r}}$ of 10300,43000 or 11600 detected.

\section{Expression of phenol hydroxylase activity in cells of E. coli BL21 or $P$. aeruginosa PAO1 carrying tbuD and its upstream promoter region}

In order to determine whether phenol hydroxylase activity was expressed in cells of $P$. aeruginosa or E. coli that had exhibited a novel peptide band of $M_{\mathrm{r}} 74000$ when grown under inducing conditions, we assayed these cells for phenol hydroxylase. As shown in Table 2, both the E. coli cells and the $P$. aeruginosa cells carrying cloned $t b u D$-bearing DNA fragments from strain PKO1, and expressing a novel peptide band of $M_{\mathrm{r}} 74000$ when grown under inducing conditions, also exhibited phenol hydroxylase enzymatic activity.

\section{Discussion}

Not only is there some apparent relationship between the strain JS150 2-monooxygenase pathway and the PKO1 phenol hydroxylase pathway as suggested by the foregoing work, but also our previous work suggests that this relationship may extend further to include a toluene-4-monooxygenase for strain JS150 [11] and the toluene-3-monooxygenase of strain PKO1 described by us [23]. Phenol is not a substrate for either the 3-or the 4-monooxygenases, but their substrate range for alkyl-substituted benzenes is similar. Alkyl-substituted benzenes and phenols are also substrates for the 2-monooxygenase of strain JS150, but only phenols are substrates for the derivatized gene product carried by strain PKO1. Interestingly, however, the organization of the pathways including the location of their regulatory genes (tbmR for strains JS150 and tbuT for strain PKO1) are juxtaposed similarly. Perhaps a progenitor strain led to the formation of strains JS150 and PKO1 which included the recruitment of the 2-monooxygenase operon for the metabolism of phenols resulting from the transformation of alkyl-substituted benzenes, but as a result of further evolution, the redundant pathways for strain JS150 had evolved in the case of strain PKO1 to more specificity and therefore a requirement for less complexity in the case of the formation of $t b u D$.

The foregoing observations suggest that for two bacterial strains showing disparate overall properties, there may be common progenitor species which have accommodated similar substrates either as a source of carbon and energy or perhaps have developed similar pathways for detoxification of their environments. Strain JS150 was isolated for growth on chlorobenzenes and its 2-monooxygenase pathway can utilize chloro-substituted benzenes as well as alkyl-substituted benzenes. Strain PKO1, however, does not transform chloro-substituted substrates either as chloro-substituted benzenes or chloro-substituted phenols. Moreover, unlike strain JS150, strain PKO1 does not carry the modified ortho pathway for chlorocatechols which might result from such transformations. A comparison of these two strains therefore suggests that, based on the organization of their respective pathways, they shared a common progenitor but further evolved to accommodate their respective environments, a chlorobenzene site for strain JS150 and a gasoline-contaminated site for strain PKO1. Incidental to this evolution for strain PKO1 was a diminution in the complexity of its phenol metabolism evolving from a multipartite enzyme to a unit peptide enzyme, but retaining the organization of its progenitor pathway, possibly a 2monooxygenase operon.

Another unusual finding of the present work is apparent lack of peptides for regions of the PKO1 pathway corresponding to the homologous regions of the strain JS150 2monooxygenase pathway. Clearly these regions are transcribed to allow expression of the $t b u D$ gene unit peptide, but do not persist to allow their isolation along with the 

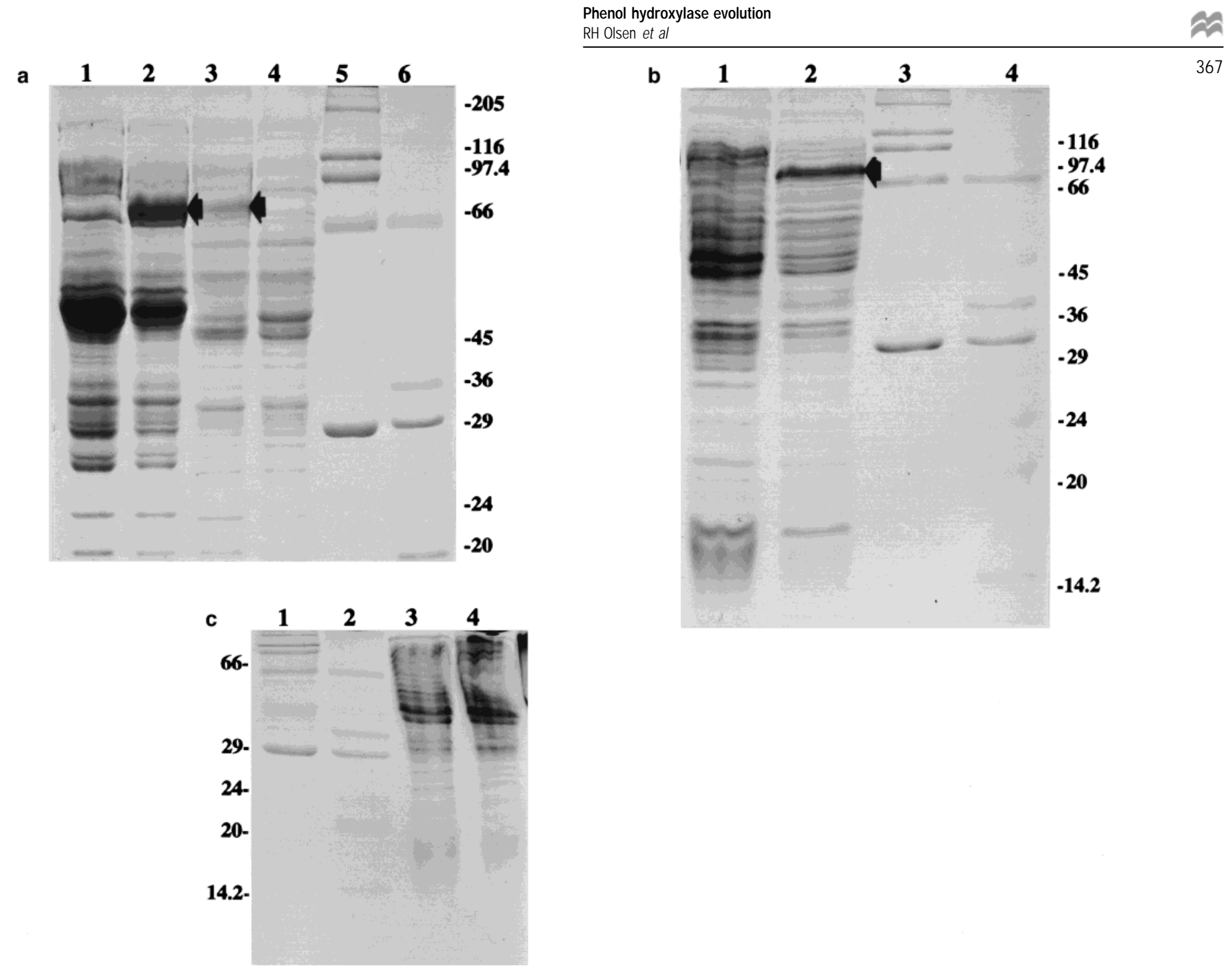

Figure 7 SDS-polyacrylamide gel electrophoretic profiles of $100000 \times g$-cleared soluble cellular proteins of $P$. aeruginosa and E. coli cells carrying DNA fragments expressing $t b u D$ and its upstream promoter region. (a) $10 \%$ resolving gel analysis of proteins from E. coli BL21 (lanes 1 and 2) carrying pBS::7.2-kb tbuD grown in the absence (lane 1) or presence (lane 2) of IPTG, and P. aeruginosa PAO1c (lanes 3 and 4) carrying pRO1963 and pRO2354 grown in the presence (lane 3) or absence (lane 4) of phenol. (b) $12 \%$ resolving gel analysis of proteins from P. aeruginosa PAO1c (lanes 1 and 2) carrying pRO1963 and pRO2354 grown in the absence (lane 1) or presence (lane 2) of phenol. (c) 15\% resolving gel analysis of proteins from $P$. aeruginosa PAO1c (lanes 3 and 4) carrying pRO1963 and pRO2354 grown in the absence (lane 3) or presence (lane 4) of phenol. Sizes of molecular weight markers $\left(\times 10^{3}\right)$ are shown to the right of panels (a) and (b), and to the left of panel (c).

Table 2 Phenol hydroxylase activity expressed in E. coli and P. aeruginosa

\begin{tabular}{lcc}
\hline Strain (plasmid) & \multicolumn{2}{c}{ Activity $^{a}$ (units $\mathrm{mg}^{-1}$ protein) } \\
\cline { 2 - 3 } & Induced $^{b}$ & Uninduced \\
\hline BL21 (pBS::7.2-kb tbuD) & $1.16(0.13)$ & $0.21(0.03)$ \\
PAO1 (pRO1963 + pRO2354) & $0.70(0.18)$ & $0.01(0.002)$ \\
\hline
\end{tabular}

${ }^{a}$ Values are the mean (standard error of the mean) of at least three separate and independent experiments. One unit of enzyme activity is defined as the amount of enzyme which in the presence of phenol causes the oxidation of $1 \mu \mathrm{mol}$ of NADPH per minute.

${ }^{b} \mathrm{BL} 21$ constructs were induced with $0.5 \mathrm{mM}$ IPTG. PAO1 constructs were induced with $0.5 \mathrm{mM}$ phenol.
tbuD gene product. This observation may suggest that the $t b m A, B$, and $t b m C$-like peptides illustrated in Figure 6 are labile in the absence of their association with the other subunits of the 2-monooxygenase ( $\mathrm{tbm}$ ) pathway.

\section{Acknowledgements}

This research was supported by the NIEHS Superfund Basic Research Program under grant ES04911. Additional partial support for nucleotide sequence analyses was provided by the General Clinical Research Center at the University of Michigan, funded by grant M01RR00042 from the National Center for Research Resources, National Institutes of Health, USPHS. We thank Lisa Ramey for her diligence in sequence analysis and for technical support. 


\section{References}

1 Abril M-A, C Michan, KN Timmis and JL Ramos. 1989. Regulator and enzyme specificities of the TOL plasmid-encoded upper pathway for degradation of aromatic hydrocarbons and expansion of the substrate range of the pathway. J Bacteriol 171: 6782-6790.

2 Birnboim HC and J Doly. 1979. A rapid alkaline extraction procedure for screening recombinant plasmid DNA. Nucleic Acids Res 7: 1513-1523.

3 Bradford MM. 1976. A rapid and sensitive method for the quantitation of microgram quantities of protein utilizing the principle of proteindye binding. Anal Biochem 72: 248-254.

4 Byrne AM, JJ Kukor and RH Olsen. 1995. Sequence analysis of the gene cluster encoding toluene-3-monooxygenase from Pseudomonas pickettii $\mathrm{PKO}$. Gene 154: 65-70.

5 Byrne AM and RH Olsen. 1996. Cascade regulation of the toluene-3monoxygenase operon (tbuA1UBVA2C) of Burkholderia pickettii PKO1: role of the $t b u A l$ promoter (PtbuAl) in the expression of its cognate activator, TbuT. J Bacteriol 178: 6327-6337.

6 Byrne AM and RH Olsen. 1996. Nucleotide sequence analysis of $t b u X$, a gene encoding a putative membrane-associated protein from Burkholderia pickettii PKO1, abstr Q-356. In: Abstracts of the 96th General Meeting of the American Society for Microbiology 1996, p 447, American Society for Microbiology, Washington, DC.

7 Cuskey SM, V Pecoraro and RH Olsen. 1987. Initial catabolism of aromatic biogenic amines by Pseudomonas aeruginosa PAO: pathway description, mapping of mutations, and cloning of essential genes. J Bacteriol 169: 2398-2404.

8 Francesconi SC, AC Blake and MS Shields. 1995. Nucleotide sequence, organization, and regulation of the toluene ortho-monooxygenase (Tom) operon of Pseudomonas cepacia G4 and its constitutive variants, abstr K-198. In: Abstracts of the 95th General Meeting of the American Society for Microbiology 1995, p 570, American Society for Microbiology, Washington, DC.

9 Hanahan D. 1985. Techniques for transformation of E. coli. In: DNA Cloning; the Practical Approach (Glover DM, ed), vol 1, IRL Press, Oxford.

10 Holloway BW, V Krishnapillai and AF Morgan. 1979. Chromosomal genetics of Pseudomonas. Microbiol Rev 43: 73-102.

11 Johnson GR. 1995. Cloning and characterization of genes encoding toluene monooxygenases from Pseudomonas sp strain JS150. PhD dissertation, University of Michigan, Ann Arbor.

12 Johnson GR and RH Olsen. 1995. Nucleotide sequence analysis of genes encoding a toluene/benzene-2-monooxygenase from Pseudomonas sp strain JS150. Appl Environ Microbiol 61: 3336-3346.

13 Kukor JJ and RH Olsen. 1990. Molecular cloning, characterization, and regulation of a Pseudomonas pickettii $\mathrm{PKO} 1$ gene encoding phenol hydroxylase and expression of the gene in Pseudomonas aeruginosa PAO1c. J Bacteriol 172: 4624-4630.

14 Kukor JJ and RH Olsen. 1991. Genetic organization and regulation of a meta cleavage pathway for catechols produced from catabolism of toluene, benzene, phenol, and cresols by Pseudomonas pickettii $\mathrm{PKO} 1$. J Bacteriol 173: 4587-4594.

15 Kukor JJ and RH Olsen. 1992. Complete nucleotide sequence of $t b u D$,

the gene encoding phenol/cresol hydroxylase from Pseudomonas pickettii PKO1, and functional analysis of the encoded enzyme. J Bacteriol 174: 6518-6526.

16 Kukor JJ and RH Olsen. 1996. Catechol 2,3-dioxygenases functional in oxygen-limited (hypoxic) environments. Appl Environ Microbiol 62: $1728-1740$

17 Laemmli UK. 1970. Cleavage of Structural Proteins During the Assembly of the Head of Bacteriophage T4. Nature (London) 227: 680-685.

18 Mercer AA and JS Loutit. 1979. Transformation and transfection of Pseudomonas aeruginosa: effect of metal ions. J Bacteriol 140: 37-42.

19 Miller JH. 1972. Experiments in Molecular Genetics. Cold Spring Harbor Laboratory Press, Cold Spring Harbor, NY.

$20 \mathrm{Ng} \mathrm{LC}, \mathrm{CL}$ Poh and V Shingler. 1995. Aromatic effector activation of the NtrC-like transcriptional regulator PhhR limits the catabolic potential of the (methyl)phenol degradative pathway it controls. J Bacteriol 177: 1485-1490.

21 Nordlund I, J Powlowski and V Shingler. 1990. Complete nucleotide sequence and polypeptide analysis of multicomponent phenol hydroxylase from Pseudomonas sp strain CF600. J Bacteriol 172: 6826-6833.

22 Olsen RH, G DeBusscher and WR McCombie. 1982. Development of broad-host-range vectors and gene banks: self-cloning of the Pseudomonas aeruginosa PAO chromosome. J Bacteriol 150: 60-69.

23 Olsen RH, JJ Kukor and B Kaphammer. 1994. A novel toluene-3monooxygenase pathway cloned from Pseudomonas pickettii PKO1. J Bacteriol 176: 3749-3756.

24 Olsen RH and J Hansen. 1976. Evolution and utility of a Pseudomonas aeruginosa drug resistance factor. J Bacteriol 125: 837-844.

25 Rothmel RK, DL Shinabarger, MR Parsek, TL Aldrich and AM Chakrabarty. 1991. Functional analysis of the Pseudomonas putida regulatory protein CatR: transcription studies and determination of the CatR DNA-binding site by hydroxyl-radical footprinting. J Bacteriol 173: 4717-4724.

26 Sambrook J, EF Fritsch and T Maniatis. 1989. Molecular Cloning: a Laboratory Manual, 2nd edn. Cold Spring Harbor Laboratory Press, Cold Spring Harbor, NY.

27 Sanger F, S Nicklen and AR Coulson. 1977. DNA sequencing with chain-terminating inhibitors. Proc Natl Acad Sci USA 74: 5463-5467.

28 Shingler V and T Moore. 1994. Sensing of aromatic compounds by the DmpR transcriptional activator of phenol-catabolizing Pseudomonas sp strain CF600. J Bacteriol 176: 1555-1560.

29 Smith AW and BH Iglewski. 1989. Transformation of Pseudomonas aeruginosa by electroporation. Nucleic Acids Res 17: 10509.

30 Studier FW, AH Rosenberg, JJ Dunn and JW Dubendorff. 1990. Use of T7 RNA polymerase to direct expression of cloned genes. Meth Enzymol 185: 60-89.

31 Worsey MJ and PA Williams. 1975. Metabolism of toluene and xylenes by Pseudomonas putida (arvilla) mt-2: evidence for a new function of the TOL plasmid. J Bacteriol 124: 7-13.

32 Yen K-M, MR Karl, LM Blatt, MJ Simon, RB Winter, PR Fausset, HS Lu, AA Harcourt and KK Chen. 1991. Cloning and characterization of a Pseudomonas mendocina KR1 gene cluster encoding toluene-4monooxygenase. J Bacteriol 173: 5315-5327. 